\title{
ERRATUM: CaIDAG-GEFI integrates signaling for platelet aggregation and thrombus formation
}

Jill R Crittenden, Wolfgang Bergmeier, Yanyu Zhang, Crystal L Piffath, Yuqiong Liang, Denisa D Wagner, David E Housman, \& Ann M Graybiel

Nat. Med. 10, 982-986 (2004)

Supplementary Video 2 was inadvertently omitted and should have been cited on page 984 together with Supplementary Video 1. Supplementary Video 2 is now provided in supplementary information online.

We regret the error.

CORRIGENDUM: CDC91L1 (PIG-U) is a newly discovered oncogene in human bladder cancer

Zhongmin Guo, Jürgen F Linn, Guojun Wu, Sarah L Anzick, Claus F Eisenberger, Sarel Halachmi, Yoram Cohen, Alexey Fomenkov, Mohammad O Hoque, Kenji Okami, Gabriel Steiner, James M Engles, Motonabu Osada, Chulso Moon, Edward Ratovitski, Jeffrey M Trent, Paul S Meltzer, William H Westra, Lambertus A Kiemeney, Mark P Schoenberg, David Sidransky, Barry Trink Nat. Med. 10, 374-381 (2004)

The formula cited in the Methods to calculate expression level and DNA copy number from real-time PCR is incorrect. The correct formula that was used is:

$10 \times 2^{- \text {(cycle number of target gene }- \text { cycle number of reference) }}$ 